Journal of Education Policy

Vol. 23, No. 3, May 2008, 287-298

\title{
Finding an identity and meeting a standard: connecting the conflicting in teacher induction
}

\author{
Jim McNally, Allan Blake, Brian Corbin and Peter Gray
}

\begin{abstract}
This article has the apparently contradictory aims of describing a discourse of new teachers that is at odds with the policy-derived competence-based discourse of the professional standard for teachers, but of also seeking to find some points of connection that may help start a dialogue between policy and research. The experience of new teachers is conceptualized as personal stories of identity formation with a clear emotional-relational dimension and a sense of self and intrinsic purpose in which others, especially colleagues and children, are central - themes not visible in the standard. The empirical context is that of new teachers in Scotland but the argument is supported through a wider literature that extends beyond the traditional limits of teacher education, drawing on, for example, notions of self-identity, pure relationship and ontological security in the work of Giddens. Whether a more constructive dialogue can begin depends partly on the extent to which the formal standard can be expected to capture the complex, personal nature of the beginner's experience, and partly on the possibility of research identifying particular areas of competence, such as understanding difference, that connect in some way to the standard.
\end{abstract}

\section{Contact addresses:}

Jim McNally, Stirling University, Stirling, FK9 4LA

j.g.mcnally@stir.ac.uk

01786466265

\section{Acknowledgements}

We are indebted to the team of practising teachers who were seconded to work as researchers on the project: Kitt Curwen, David Dodds, Lesley Easton, Colin Smith, Phil Swierczec and Lesley Walker. We also thank the co-directors of the project: Nick Boreham, Peter Cope and Ian Stronach. 


\section{Finding an identity and meeting a standard: connecting the conflicting in teacher induction}

\section{Introduction}

The induction of new teachers in Scotland is formally expressed in a policy framework that consists of the Standard for Full Registration (SFR) and a support scheme for new teachers. This was developed by the then Scottish Executive and the General Teaching Council for Scotland (see http://www.gtcs.org.uk) as policy partners in a jointly funded induction project. The 'benchmark' standard provides generalised statements of knowledge, skills and values that are needed to become a fully registered teacher. The support scheme offers to new teachers (traditionally known as probationers in Scotland) a guaranteed one year training post; a maximum class commitment of 0.8 full time equivalent; access to an experienced teacher as a nominated supporter; a starting salary that compares well with other professions; dedicated time for professional development. This initiative was a national policy response to concerns about the fragmented experience of many new teachers (McNally 2001), a situation reflected in many countries and described in a number of publications in recent years (e.g. Flores 2006; Tickle 2000).

Our evidence for this paper draws mainly on research data from the early professional learning of new teachers (the EPL Project ${ }^{\mathrm{i}}$ ). The data base comprises a set of ethnographic interviews which took place every few weeks during the first year of teaching, thus providing a more sustained narrative base of evidence. These interviews were conducted by six teachers in the research team, in their own schools and covering 28 new teachers in total, and so are also informed by knowledge of local context. The transcribed interviews are a rich source of evidence of a discourse for new teachers' experience that is largely at odds with the standard as written: new teachers make very little reference to the formal standard. The two discourses have been portrayed for many years as conflicting and even incompatible representations of teacher induction (e.g. Stronach et al 1994), perhaps even illustrating a trend of policy that is 'impatient with the non-standard' and instead 'seeks uniformity and homogeneity in order to permit the operation of its auditing' (Ozga 2000: 233).

Although this paper acknowledges and also illustrates a discursive divide, it attempts to step beyond the tradition of unmitigated criticism of competence-based standards and examine the possibility of a more connective and constructive dialogue between policy and research. This is done in the course of developing a conceptualisation of the discourse of new teachers' experiences in terms of personal stories of identity formation with a strong emotional-relational dimension that reveal a sense of self and intrinsic purpose. Whether there is a space within the national polity for exploring potential connections remains to be seen but it should be clear that neither our research rationale nor our argument is driven by a policy imperative to solve a problem or to find what works. The extent to which we agree with Shain and Ozga (2001: 117) that there is little scope for the immediate involvement of research in a policy agenda for improved standards and performance ('delivered through target setting, monitoring and disciplining of the teaching profession') will depend on the extent to which we are able to influence 
the guardians of the standard. By acknowledging the local and the contingent in the experience of beginning teaching, we may manage to move behind the scenes of policy making to show that one size (or standard) does not fit all.

\section{Conflict or connection}

A striking feature of the narrative data, as indicated earlier, is that new teachers do not readily relate to the SFR in talking about their teaching:

I would be reading and half way through I would just give up in disgust

I found it really dry ... it wasn't seeking to find anything about me personally as a teacher.

Yet all 28 teachers in the sample achieved the SFR (one requiring an extension of placement). It is not that they were incompetent teachers - quite the opposite in most cases - but there was no reference to the SFR or its component parts in the interviews, other than when mention was made of the official interim report (based on the SFR), some four months into the first year of teaching. It tended to be used at that point as a checklist to fulfil a bureaucratic requirement. We would suggest that this is because the SFR cannot capture the essence of classroom teaching for beginners and is not a useful reference for them in making sense of their everyday teaching, at that stage of development. It is inevitably general in its expression and serves a rather different purpose, perhaps more accurately as a statement of public accountability.

Nevertheless, transcripts were closely scrutinised for implicit connections to statements of competence contained in the SFR. One of the few examples was the new teacher's developing sense of difference (between classes, lessons and individual children):

I've learnt that no two lessons are the same, that no two classes are the same and not to expect them to be the same and, though you're preparing the same work, it never works out the same ... at first I was a bit concerned and I thought well maybe I wasn't teaching it correctly, especially the first time I taught the lesson and there was an element of thinking that you can change this or change that, but you need to know that kids are different and different things work for different kids.

Allowing for the difference in register, there is a similarity of meaning here with this extract from the SFR (GTCS 2001):

registered teachers ... ensure learning tasks are varied in form, differentiated and devised to build confidence ... select strategies for teaching and learning appropriate to the subject, topic and interests and needs of pupils .... use and adapt materials for learning and teaching which stimulate ...

Even so, isolated examples such as the above still indicate a degree of disparity between the ordered expression of the official standard and the actual experience of learning articulated by new teachers. It is not that the intention of the formal extract above is in dispute, but it is a description which does not reflect the process of coming to appreciate 
specific differences in children and of then finding ways of working that accommodate these differences. It seems clear that support and standards for new teachers should allow for the time they need to develop an understanding of such differences in their specific context. They need opportunities to explore the meaning of difference in their teaching world in a way that can focus on a particular 'competence' at that stage, without losing sight of the wholeness and complexity of their own learning and development.

\section{The emotional-relational dimension}

The process of learning to teach is also characterised by its emotional involvement. Teaching itself causes anxiety and apprehension, satisfaction and delight. Emotional language is frequent in the interviews with the new teachers e.g. 'butterflies', 'nerves, panic', 'waking at two or three', even in anticipation of their first day. Yet anxiety over 'class control' tends to be bound up in a developing knowledge of children as individuals and collectively as a class. This development itself tends to be expressed by the new teachers in affective terms, for example 'pleased', 'liked' and 'happier'. The first days and early weeks of teaching are emotionally charged with so much compressed into a short period. They talk of being on an 'emotional roller coaster'. It does appear that there is little option but to enter life as a teacher through a kind of emotional labour that is in effect an investment in the formation of relationships that are fundamental to the beginner's sense of development as a teacher. This relationality is a major conceptual theme in the interview data and supports tentative findings from earlier small scale research on the prevalence of informal learning in the form of 'natural mentoring' (McNally 1994) and the existence of 'relational conditions' (McNally et al, 1997). Other studies too support the idea of an emotional and relational dimension in the lives of teachers. Hargreaves (1998), for example, sees the emotions of teaching as 'not just a sentimental adornment ... (but) ... fundamental in and of themselves'. In his extensive study of informal learning in the workplace, Eraut (2004) argues that the 'emotional dimension of professional work is much more significant than normally recognised'. He also found that 'informal support from people on the spot' when help is needed tends to be more important than that from formally designated helpers or mentors.

Little mention is made in the interviews of what might be described as more cognitive aspects of development, such as subject knowledge, lesson planning, practical teaching insights. New teachers are of course meeting the professional standard so we might infer that knowledge and skills that we typically associate with the teacher's work are somehow being acquired, or are at least adequate for teaching at this early stage. Eraut (2000), for example, refers to the implicit learning and tacit knowledge of teachers. It may be that there is a latent cognitive dimension of learning to teach that emerges in a later post-traumatic phase of development. In this early phase, however, it is the emotional and relational dimensions of learning that come to the fore.

In his more general theory of learning, Illeris (2002) identifies the cognitive, the emotional and the social as the three dimensions of learning. The term relational is preferred to social in this context as there are clearly identifiable, developing relationships in beginning teaching, essentially with colleagues and pupils, and these are 
fundamentally important beyond the merely social. They feature so prominently in the narratives that they almost define the job of teaching at that early stage of development. The individual's sense of becoming and being a teacher is bound up in these developing relationships.

\section{Identity in context}

The narrative base of evidence is a set of stories in which beginners face the fundamental question of whether they can see themselves as teachers in what is reflected from colleagues and children in their various interactions. Their challenge is whether they as individuals can adapt to and become accepted in a new relational context. It is important to recognise that this process of becoming a teacher is not simply a derivatively social experience, some form of passive socialisation. Each individual's evolving narrative can be read as the voice of a personal struggle through a more or less reflexive engagement with the experience itself. Even in the new policy context of a formal induction system, the evidence is still that new teachers find their sense of their 'new' professional selves through their developing relationships with colleagues and pupils, largely outside the formal system, and with little reference to the professional standard. The concept of identity formation here is somewhat more limited than in many other analyses (e.g. Sikes, Measor and Woods, 1985; Stronach et al 2002), where the multi-faceted and provisional nature of identity is emphasised. The explanation of this difference lies in the fact that the personal change taking place in new teachers is grounded in that specific and brief, beginning period when the development task is well defined - to become accepted as a teacher by your pupils and colleagues.

Relationality and emotionality, major themes though they are, should not therefore occlude the personal and individual nature of the narratives, the unfolding situations and sense-making by the beginners themselves which feature themselves. Our concept of identity, therefore, also needs to accommodate some notion of developing individuals. It has to include some sense of the unique persons who, in their developing biographies, are becoming teachers. The unfolding narratives as biographical episodes do not convey personal change as some sudden alteration in behaviour or self-concept. Each one is rather more like a story of self-discovery, a growing reflexive awareness that a self-asteacher is becoming possible. For some it may be about the emergence of qualities within oneself: one beginner talks of recognising the emergence of 'humanity' and 'humility' within herself as she becomes aware of the difficulties that some children experience in their lives. For others it is not quite possible to articulate the change, though change itself is acknowledged.

Giddens (1991) uses the term 'self-identity' to mean 'the self as reflexively understood by the person in terms of her or his biography'. Although it is but one of many potential stories that could be told about one's self, and is thus 'fragile', it is also 'robust' in that it can be secure enough to allow the person to cope with a transition and inherent tensions in a given context. Thus, there is the emergence of a revised self that has within it a teacher identity, typically after several weeks of emotional turmoil and vulnerability. The 
individual is provisionally acquiring a new sense, in Giddens' words, of 'ontological security' (p.36).

It is not only because of the emotional and relational themes identified in data classification, but from the individual narratives themselves, that there is a clear case for equating learning to teach with forming an identity as a teacher. This equation seems particularly evident indeed when the new teachers attempt, as in the discourse discussed earlier, to relate to formal profiling and the SFR:

It doesn't give anything of me, you know 'Rachael the teacher'. It's just like a ticky box style.

'Ticky boxes' are only about what is supposed to have been learned. Rachael can feel some security in her identity as a teacher only if she has to keep on learning:

I guess as a teacher learning that you don't have all the answers and it's okay that you don't'

In an extensive longitudinal study of teachers by Day et al (2005), identity is seen as a fundamental construct for understanding teacher effectiveness and improvement. A plausible inference is that the early months and years of teaching may be fairly crucial in the formation of that identity. Given the emotional turmoil and personal change that pervade the experience, we might expect this to be acknowledged somehow in a standard for new teachers that is, perhaps predictably, somewhat impersonal. It is, however, a transition, that is clearly located within the broader learning theory of Illeris (2002):

Very special and demanding situations, often with a crisis-like character, can lead to deep and comprehensive transformative learning processes that include simultaneous change in all the three learning dimensions and have to do with the very identity of the learner (p.229)

This kind of general theory accommodates the empirical data and grounded interpretation, making it more possible to see beginning teaching as a deep process of personal change in which there is an emergence of a teacher identity.

\section{An individual self}

Given the personal nature of the data, any meaningful construct of identity surely has, as we have begun to argue, to accommodate a sense of self. As one new teacher put it, 'you have to give of yourself but not be yourself'. Much of the emotionality in the narrative accounts, particularly in relating to children, suggest the embedding of a personal commitment (included in the SFR) within individuals whose identity may be associated, as Greenwood (1994) would argue, with their engagement in a moral career. The raw data for this paper is a set of individual stories, each with an emerging self-as-teacher identity, closer perhaps to a notion of self-identity (Giddens 1991). Hoveid and Hoveid's (2004) 'relational self' also conveys a notion of agency in a self that is nevertheless intrinsically dependent on pupils and colleagues (and significant others) for its emergence and expression. In this brief quote, a new teacher has become aware of her new 'self-asteacher', disturbing otherwise close relationships outside school: 
Personally I find it difficult to get out of teacher mode. I've gone home and I've got into trouble from my mum because I used the tone and words I would use to pupils like 'Stop speaking to me like that' and she just looked at me and said you're not a teacher now you know, and I said 'what?' because I didn't realise I was doing it, and my boyfriend's always on at me, saying stop treating me like one of your pupils ... That's one thing I'm definitely struggling with, speaking to people out of the classroom like pupils!

In a recent seminar series ${ }^{\mathrm{ii}}$, many of the contributions feature the individual's story: Burn (2005) on the male early years teacher; Daly and Maguire (2005) on becoming a black manager; van Zanten (2006) on new teachers' emerging humanitarian ethic in French schools. It is difficult to deny the integrity of each person's story in our attempts to theorise the early experiences of teaching. In such accounts (including those of the EPL Project), it is clear that people do bring their individual abilities and unique experiences to their new school or workplace and that working there contributes to their developing 'worker' identity.

In relation to teacher development, Tabachnik and Zeichner (1983) have made the point that what students themselves bring as individuals to the experience and what part this plays in their own development, should not be underestimated. Reid (2001), in a keynote speech to the Universities Council for the Education of Teachers expressed the concern that the development of theory and policy should not overlook the intrinsic personal qualities and diversity of talent that new teachers bring to their work. The process of becoming a teacher is thus an extension of these various individual biographies, through drawing on the existing capacity and personal qualities of different individuals for teaching, but also through a degree of change in the unique identities they bring to the task. Though our theorising applies to beginning teachers in schools, individual biography has been found to be significant in workplace learning more generally (Hodkinson et al 2004); moreover, it is so in a similar way, in 'bringing prior abilities and experiences to the workplace ... (and in that) ... participation in work contributes to the construction and development of worker identity'. As Ann reflected:

I don't think I ever properly realised that the position I have as a teacher ... that I do hold quite a position of responsibility ... I had to be a lot more guarded about certain things ... I've actually got to change coming from Dundee ... even the way I talk I've got to adjust that ... it's just bizarre ... I'm very much somebody that's quite animated and sometimes having to tone that down ... you kind of have to have some of your personality in the classroom'.

Indeed, Alheit and Dausien (1999) actually write of 'biographicity' to mean the capacity that people have that can not be taught by experts, their uniqueness as a resource for building new relationships. It is surely important, therefore, that we recognise the limitations of standards and formal courses of professional 'development' in their potential to influence how and what people learn and the change that they can bring about. It is often people's individual experiences, qualities and capacities that enable 
them to perform (or, indeed, prevent them from performing) - in the classroom or elsewhere.

We alluded in previous work (McNally et al 1997) to a sense of a 'personal struggle' by beginners and the 'more or less existentialist predicament' in which they found themselves. Within the prominent theme of 'others' in the experience, we proposed that some concept of 'self' ought to be somehow accommodated in any attempt at a full explanation. This argument is not for recognition of self as a pure, abstract concept but on the basis of the particular stories and situations that are revealed through interview with individuals. Our concept of self is thus more aligned with that of Bakhtin who argued that self can never be a self-sufficient construct (Holquist 1990), and whose work placed radical emphasis on particularity and situatedness; abstract questions about selfhood could indeed only be pursued as specific questions about location.

Our findings also direct us towards the paradigm of many educational ethnographers (e.g. Eddy 1969) that assuming or adapting to a new identity in the sense of 'becoming a teacher' is a more authentic representation of the beginner's actual experience than the more rational, cognitive notion of learning to teach. The specific context of our study is also illustrative of the more general theory that learning is an inherently emotional process embedded within a relational context closely associated with the development of self and identity (Bosma and Kunnen 2001).

\section{Personal purpose in teaching}

A further observation to be made on the substance of the narratives is that their content self in relation to pupils and colleagues - reveals what matters to the interviewees. That colleagues play a major part in the working life of the beginner is a common feature of many workplaces. Inscribed in relations with others in the workplace, Hinchcliffe (2004) claims that there is an ethical nexus, and that this is inescapable and bound up with technical skills. His argument is that the ethical dimension of relationships at work is important for human flourishing and for the quality of work that is done, provided they are not treated in formal performative terms. The research data for beginning teachers supports this position: the relational nature of their development is not only a means or context for learning (to teach) but is an integral part of what it means to become, and probably to continue to be, a teacher. However, it is the variety of interactions and developing relationships with children in classes that essentially distinguish teaching from other occupations. The permeation in interviews of developing relationships with classes and the different 'pupils' within them, suggests that this is what gives individually felt meanings to the early experience of new teachers. Thus it is not only a question of being 'identified' by children as 'their' teacher - and thus becoming a teacher in a real and relational sense rather than in official, standardised terms - but of this being what in fact matters most to the individual new teachers, the experience through which they feel their own initial sense of purpose.

This interpretation of this specific phenomenon evokes the broader existentialist view that what tends to stand out in our experience is what matters to us. Citing Heidegger and 
Kierkegaard, Guignon (2000), for example, states that 'discernment and differentiation are possible only for a being that cares about what it encounters' (p.83). The developing relationship with classes is a major theme in the narrative data. Furthermore, the interpersonal and emotional nature of its expression suggests that the growth of new teachers into their new 'professional' role involves a degree of personal commitment by them as individuals. It should be recognised that "personal commitment and professional values' do constitute one of the three categories of performance (along with knowledge and understanding, skills and abilities) in the SFR. However, the richness of the narrative data base leads us to at least a conceptual elaboration of what this might mean experientially. The personal commitment is clearly themed in the series of interviews as a developing emotional engagement by individual new teachers; it is a commitment that both influences and depends on the very self-identity of these beginners.

Nor do values appear to be associated with any formally espoused rhetoric about what matters. Values are bound up in the emotional-relational journey of discovery of self and others. Individual new teachers are internalising their own sense of purpose in a worthwhile cause in which their own early experiences in the world of teaching are extensions of their own personal histories. This is not to say that programmes of induction and initial teacher education, which must reflect policy guidance to a degree, have no relevance; it is just that they have to be seen as but one of a range of potential influences that are only likely to achieve meaningful impact if they connect to the central core of professional development that is the personal sense of purpose in teaching within each individual biography.

The conceptual cluster of emotionality, relationality and self-identity are presented here as major themes in the data but it is evident that they are closely interwoven and indeed integral to the learning process that is defined by the experience of becoming a teacher. They are perhaps amore credible conceptual triad (than the SFR triangle of knowledge, skills and values) within which the beginner experiences meaning and purpose. The ethical nexus (Hinchcliffe 2004) of these relationships is important in itself, as a performance end as much as means. Building from the earlier small scale research to the current EPL Project, it has been argued elsewhere (McNally 2006) that the cumulative evidence base suggests a conceptual journey from the prevalence of informal learning to the centrality of identity formation. Despite a degree of definitional vagueness surrounding informal learning, its importance has been highlighted by others (e.g. Coffield 2000, Eraut 2000). A particularly telling point is made by Smith (2003) who further argues that there is purpose in informal learning through the concern to build the sorts of communities in which people can be happy and fulfilled.

Beginners in teaching face the fundamental question of whether they can see themselves as teachers, not only in the reflections from colleagues and children in their schools, but also in the mirror that they hold up to themselves. What they articulate in interviews are often different personal qualities rather than any values or skills prescribed by a professional standard; they are personal attributes the new teachers discover or seek within themselves that will enable them to accommodate the demands of the job. This search for a teaching identity has a strong individual dimension. For example, one 
beginner talks of recognising the emergence of 'humanity' and 'humility' within herself, as she begins to understand the real difficulties that some children experience in their lives. It is as if her learning identity emerges from and through an emotional response to a developing relationship with children. It is within this emotional-relational experience that beginners discover their personal commitment, their implicit values and their intrinsic sense of purpose.

\section{The voice of children}

There are many references to children in the interviews, typically in terms of a developing knowledge of them as different individuals. This is a reciprocal process in that children also begin to see the new teacher as an individual. As this develops more or less successfully (and the interviews suggest that it does in all but two cases), then the teacher-pupil relationships build into a working classroom community. As one new teacher put it, you are 'a person in a class' and you become accepted as a teacher when 'kids start to see you as a person'.

One aim of the EPL project was to develop an indicator of 'children's descriptions of new teachers' (EPL website, children's view indicator). Its design involved seeking responses from children in classrooms through our teacher-researchers. Of over 1000 individual statements from children, some $25 \%$ described their teachers in terms of personal qualities (e.g. humorous, relaxed, understanding, friendly, considerate, kind, forgives, not moaney, pays attention to you, happy excited, fair .... mean, shouts, bad moods, scary, angry, laughing at you, has favourites, embarrasses you ) rather than in terms of teaching skills. This echoes findings from the Hay McBer study (2000), prior to their categorisation of performance levels of teachers: a good teacher, for example, 'stands up for you ... tells the truth ... has faith in you ... is generous'.

As in other work on the pupil voice (e.g. Ruddock and Flutter 2004), we found that pupils very rarely personalised their criticisms. Like them too, many teachers in our collaborating schools have sought to use the instrument in a formative, self-evaluative capacity, in some cases using the pupil feedback to change their practice. The language that pupils use is also much more specific and practical in a way that teachers can make sense of, in contrast to the decontextualised abstractions of a written standard. It seems that pupils see the person that resides within the teacher, or that is the teacher. In voicing such human qualities of their teachers, children themselves show some need to trust or believe in their teacher as a person.

Many children may need a sense of 'ontological security' (Giddens 1991) themselves from their teachers. The security is reciprocal of course, for new teachers are also dependent on their pupils, not only for offering a sense of professional purpose, but also for their very acceptance as a teacher, as argued above. They draw their self-as-teacher identity and their own ontological security from children, as well as colleagues. This reciprocal ontological security is indicative of the teacher-pupil interdependence developing toward something approaching a 'pure relationship' (Giddens 1991) which depends on mutual trust, in which the trust of the other has to be won, in which the 
individuals have to be trusting and trustworthy within the confines of the relationship, and in which self-identity is negotiated through linked processes of self-exploration and shared histories. We would argue that this mutuality and interdependence is fundamental to the new teachers' experience and identity formation, and that it transcends the policy checklist, however well intentioned, of a professional 'standard'.

\section{Concluding Discussion}

It is important to clarify what is not being argued. Clearly, teaching is dependent on a wide range of knowledge and skills and is not simply about identity formation. In a sense the new teachers are, of course, gaining knowledge about their classes and the individual pupils within these classes. They are also coming to terms in most cases with new locations, physical layouts, accommodation, resources and procedures - and we acknowledge these structural, physical and cognitive dimensions in the general project findings. However, the narrative base of our data did not uncover during the first few months any strong occurrence of references by new teachers to subject knowledge, teaching methods or any of the standard conceptual apparatus of either professional standards or ITE courses. Pedagogical content knowledge was simply not a feature in their discourse. Nevertheless, our view is that, although it is largely unseen in our data, there is a cognitive dimension of learning to teach. Glimpses of it begin to surface in a few of the narratives after about four months into teaching. There is the example of differentiation referred to earlier; another is beginning to adapt existing lessons and resources to their own developing style - so there may be more to uncover on potential cognitive engagement and a possible discursive connection in the later stages of induction. It may be that it is temporarily bracketed by new teachers as what they want to develop next.

It may well be that new teachers 'survive' this traumatic first phase of starting teaching on the basic knowledge and skills from their ITE courses (including teaching as students in schools). If no new knowledge and skills appear to be learned, it is therefore submerged in interviews, relegated below the more pressing concerns of making their own sense of a new and complex world, of belonging and being accepted in it and of thus gaining a teacher identity. Our evidence is that beginning teaching is indeed demanding for just about all beginners and is special for each beginner. While it may not approach a crisis for every new teacher, it is more or less transformative for all of them, and that is why the transition has to be recognised as an identity shift rather than as any rational policy-governed progression through the elements of a standard.

What does this imply for the preparation of teachers? Ideas such as the argument of this paper, which we claim is well grounded, cannot just be rendered superfluous because they are not easy to prescribe through theory or sensible policy. Nonetheless, formal statements should surely acknowledge that teaching cannot just be assimilated as a craft or set of technical skills (e.g. clarity of voice, use of power point), or even as parts of professional knowledge (e.g. a Maths curriculum or approaches to difference). The various standards and collections of competence requirements lay out laudable, vaguely 
articulated aspirations that may help illuminate but cannot of themselves hold the key to successful teaching or acceptance as a teacher.

The SFR ought to be seen as a first attempt to frame professional learning outcomes that now needs to be moved on to next stage of revised text in which the importance of emotional engagement and personal qualities are acknowledged. This will need a dialogue between researchers and policy makers, in which the conceptual gap between professional or occupational standards and workplace (school-based) learning is explored, a problem not unique to teaching. The writing of the SFR itself was the product of a rare collaboration between the policy and research communities (McNally 2001). For a short while, in a slightly strained spirit of reciprocal enlightenment, they worked together to, in effect, transfer knowledge before that noble aspiration became commodified as 'knowledge transfer' (Ozga 2006). The final document at least acknowledged the possibility that practitioners might use more holistic professional judgements (research-based) alongside more specific competence statements (policybased). A few examples of 'holistic quality indicators...(of)...an individual's capability....respect of pupils in classes taught; being valued by other members of staff; having a purposeful class ethos; being trusted by parents; enabling pupils to make good progress' were grudgingly given as 'not a formal part of the SFR...but...could provide a useful way of supporting judgements made when reviewers are discussing progress with new teachers or completing their reports at the end of the induction period' (GTCS, 2006).

This was but an initial step of course and it remains to be seen whether, as an occupational standard, the SFR will evolve in due course to have the linguistic or political capacity to absorb concepts such as emotion, identity and ontology. Another important question will be the extent to which an evolving standard compares with the 'experiment' in the Netherlands where the previous, centrally driven standard was officially acknowledged to have failed and was replaced by one devised by practising teachers. This new professional standard is a framework which 'accentuates the teacher's prime role in relation to pupils' and provides extended descriptors that 'relate predominantly to teaching and learning processes'. In researching this, Storey (2006) found evidence in her interviews with teachers of a discourse that reflects the importance of human qualities ('you can learn how to teach but it is difficult to learn to be a good person'), a holistic sense of competent or incompetent teaching ('pupils are not happy in the classroom') and the centrality of relationships ("interactive with children ...capacity to deal with parents and colleagues).

What is not easy to resolve is the extent to which personal qualities and an individual's capacity to do a particular job well, including the ability to teach children well, could be captured in any quantifiable way - or whether certain qualities remain unmeasurable. While this paper has sought to avoid debating this seemingly perennial polarisation of positions, it is surely the case that the preparation of teachers (in ITE and induction) should involve the nurturing of them as individuals. They need support as empathetically as possible in releasing their individual qualities and in building their confidence and capacity to do the same for others. It is again important to recognise that this has to be 
balanced with the need to develop more or less agreed sets of knowledge and skills, and subsequent research should be able to offer indications of the kind of input that matches stages of professional learning, in as much as these can be identified. For example, a few of our subjects identified worthwhile instances of formal presentations arranged by their local authority, notably on 'getting to know your class' and on 'behaviour management'. These appear to have been well received by new teachers during the first few months. Such inputs may well match the concerns that most new teachers have at that time although their success appears to owe as much to the quality of the individual presenters than to the topic itself. The main point remains, however, that over-emphasis of knowledge and skills, through cramming just about all the experienced teacher would need to know into a curriculum for induction or ITE, runs the risk of squeezing the space for more sensitive input.

The tension in teacher education between the formality of theory and standards and actual experience and practice also exists in Sweden. For example, Carlgren (1996) actually argues that there is a contradiction between the tacit knowledge that teachers draw on in practice and the formal theoretical knowledge about teaching and learning that tends to dictate what they ought to do. Her view is that formal knowledge needs to be grounded in, or integrated with, tacit experience-based knowledge, particularly in the social dimension of learning. Within a structure that offers reasonable coverage of 'expected' topics, it is, therefore, important to resist the presumption that standards and other national policy statements can, as currently constructed, adequately define a curriculum for induction or ITE, as in the need to resist demands for ready made solutions for behaviour management, for example (McNally et al 2005).

We need to begin an exploratory dialogue with the policy-making community that is not a meeting of polar opposites but which recognises the relative absence of reference to the SFR in interviews; acknowledges the emotional as well as the cognitive, the ontological as well as the epistemological; and asks to what extent formal standards and support systems can be expected to capture the complex, personal nature of the beginner's experience. A standards-centred or competence-based discourse may have a place then in the rhetoric of product rather than process. The discourse of new teachers and the grounded concepts of this paper may be seen as complementary to the meta-language of policy but only if their role in understanding the early development of teacher is acknowledged in practice and in policy. We have a little empirical evidence but no theoretical sense of how specific competence statements are or could be meaningfully used by practitioners. It may be possible to discover whether some competences, as in the example of differentiation above, are more important or more stage-critical than others but this would require a more focussed and extended study to provide, in the words of Halliday (2004), rich descriptions of becoming competent and the contexts in which it happens.

\section{References}


Alheit, P. and Dausien, B. (1999) 'Biographicity' as a Basic Resource of Lifelong Learning Paper presented to European Conference on Lifelong Learning, University of Bremen

Burn, E. (2005) 'Working with the ankle biters': constructing the male early years teacher, CTRIP seminar series, King's College London

Bosma H.A. and Kunnen E.S. (2001) Identity and Emotion (Cambridge University Press)

Carlgren, I. (1996) Professionalism and Teachers as Designers in M. Kompf et al (eds.) Changing Research and Practice (London: Falmer)

Coffield F. (ed.) (2000) The necessity of informal learning ESRC Report (Bristol: The Policy Press)

Corbin B. (2006) Professionalism on Probation: induction and new teachers in Scotland and England, working paper, EPL website: http://www.ioe.stir.ac.uk/Research/Projects/epl.htm

Daly, D. and Maguire, M. (2005) Becoming a black manager, CTRIP seminar series, King's College London

Day C., Kington A. and Gu Q. (2005) The Role of Identity in Variations in Teachers' Work, Lives and Effectiveness paper presented at ESRC Seminar Series University of Nottingham

Eddy E.M. (1969) Becoming a teacher (Columbia University, Teachers College Press)

Eraut, M. (2000) Non-formal learning, implicit knowledge and tacit knowledge in professional work, in Coffield F. (ed.) The necessity of informal learning ESRC Report (Bristol, The Policy Press)

Eraut, M. (2004) Informal learning in the workplace Studies in Continuing Education 26, 2, 247-273

Early Professional Learning (EPL) Project website http://www.ioe.stir.ac.uk/EPL/index.htm (accessed 20 January 2007)

Early Professional Learning Project website children's view indicator http://www.ioe.stir.ac.uk/research/projects/epl/docs/cepsatiS.pdf

Flores M. A. (2006) Being a Novice Teacher in Two Different Settings: Struggles, Continuities, and Discontinuities Teachers College Record 108 (10) 2021-2052

General Teaching Council for Scotland (2001) The Standard for Full Registration Appendix 1 (Edinburgh: GTC Scotland)

General Teaching Council for Scotland (GTCS) website (2006) http://www.gtcs.org.uk/web/site/Probation/StandardFullReg (accessed 2 August 2006)

Giddens A. (1991) Modernity and Self-Identity Cambridge Polity Press

Greenwood J. D. (1994) Realism, Identity and Emotion London, Sage Publications Ltd.

Guignon (2000) Philosophy and Authenticity: Heidegger's Search for a Ground for Philosophising In Wrathall M. \& Malpas J. (eds.) Heidegger, Authenticity and Modernity Mass. MA, MIT

Halliday, J. (2004) Competence in the Workplace: Rhetorical robbery and curriculum policy Educational Philosophy and Theory 36 (5) 579-590

Hargreaves, A. (1998) The Emotional Politics of Teacher Development Keynote address to AERA San Diego U.S.A.

Hay McBer Report (2000) A Model of Teacher Effectiveness www.dfee.gov.uk/teachingreforms/mcber 
Hinchliffe G. (2004) Work and Human Flourishing Educational Philosophy and Theory 36 (5) 535-547

Hodkinson P.Evans K, Fuller A. Hodkinson H., Kersh N. Senker P and Unwin L (2004) The significance of individual biography in workplace learning Studies in the Education of Adults 36,1 Spring

Holquist, M. (1990) Dialogism: Bakhtin and his world New York Routledge

Hoveid, H. and Hoveid, M. (2004) A Teacher's Personal Language: Ways of Constructing Inclusion and Diversity in Teaching Paper presented at the annual European Conference on Educational Research Crete

Illeris K. (2002) The Three Dimensions of Learning (Leicester, Niace Publications/Roskilde University Press)

McNally J. (2006) From informal learning to identity formation: a conceptual journey in early teacher development Scottish Educational Review Special Edition Teacher Education and Professional Development, 37 (79-90)

McNally, J. (2001) The Induction of New Teachers in Scotland: A Report for the General Teaching Council for Scotland and the Scottish Executive Department (Edinburgh, GTC Scotland)

McNally, J. (1994) Students, Schools and a Matter of Mentors The International Journal of Educational Management 8, 5, 18-23

McNally J., I'Anson J. Whewell C. and Wilson G. (2005) 'They think that swearing is okay': first lessons in behaviour management Journal of Education for Teaching 31, $3,169-185$

McNally J. \& Oberski I. (2003) Right at the start: an agenda for research and development in teacher induction Teacher Development 7, 1, 59-73

McNally, J., Cope, P., Inglis, W. \& Stronach, I. (1997) The Student Teacher in School: Conditions for Development Teaching and Teacher Education 13, 5, 485-498

Ozga, J.\& Jones,R. (2006) Travelling and embedded policy: the case of knowledge transfer Journal of Education Policy 21, 1, 1 - 17

Ozga, J. (2000) Education : New Labour, New Teachers, in J. Clarke, S. Gewirtz \& E. McLaughlin (eds) New Managerialism, New Welfare? London: Sage

Reid, I. (2001) The neglect of the ITE student in the reform of ITE in England and Wales in the 1990s, in Reid, I. (ed.) Improving schools: the contribution of teacher education and training London: Universities Council for the Education of Teachers

Ruddock, J. \& Flutter, J. (2004) How to improve your school; giving pupils a voice London, Continuum

Shain, F. \& Ozga, J. (2001) Identity Crisis? Problems and Issues in the Sociology of Education British Journal of Sociology of Education, 22:1, 109-120

Sikes, P., Measor, L. \& Woods, P. (1985) Teacher Careers: Crises and Continuities Lewes, Falmer

Storey, A. (2006) The search for teacher standards: a nationwide experiment in the Netherlands Journal of Education Policy21, 2, 215-234

Stronach, I. Corbin, B., McNamara, O., Stark, S. \& Warne, T. (2002) Towards an uncertain politics of professionalism: teacher and nurse identities in flux Journal of Educational Policy 17, 1, 109-138 
Stronach, I., Cope, P., Inglis, B. and McNally, J. (1994) The SOED 'Competence' Guidelines for initial teacher training: issues of control, performance and relevance. Scottish Educational Review 26, 2, 118-133

Smith, M.K. (2003) http://www.infed.org/i-intro.htm (first published May 1997, last update December 2003)

Tabachnik, B. R., \& Zeichner, K. M. (1983) The impact of the student teaching experience on the development of teacher perspectives. Madison, WI: Wisconsin Centre for Education Research.

Tickle, L. (2000). Teacher induction: The way ahead. Buckingham, England: Open University Press

Van Zanten, A. (2006) The new generation of teachers in France: views on professionalism in a changing policy context, CTRIP seminar series, King's College London

\footnotetext{
i 'Enhanced competence-based learning in early professional development' is a four year research project (2004-2008) that is part of the Teaching and Learning Research Programme funded by the Economic and Social Research Council of the UK

ii 'Changing teachers' roles, identities and professionalism' (C-TRIP) is a seminar series funded by the Economic and Social Research Council of the UK
} 